\title{
CONTRIBUIÇÃO DOS PROJETOS DE INICIAÇÃO CIENTÍFICA NA ÁREA DE CIÊNCIAS AMBIENTAIS PARA O DESENVOLVIMENTO SUSTENTÁVEL
}

\author{
Marcia Aparecida Andreazzi ${ }^{1}$ \\ Ludhiana Ethel de Matos Garbúgio² \\ José Maurício Gonçalves dos Santos ${ }^{3}$ \\ Luiz Felipe Machado Velho 4 \\ Isabele Picada Emanuelli ${ }^{5}$
}

Resumo: A iniciação científica promove a busca de soluções para problemas em diferentes áreas do conhecimento, por isso este trabalho analisou os projetos de iniciação científica relacionados à área de ciências ambientais em uma IES privada, entre os anos de 1998 a 2018. O estudo revelou poucos projetos voltados às questões ambientais $(11 \%)$, sendo a maioria $(71,64 \%)$ realizada nos últimos 6 anos, da categoria PIC (58\%), desenvolvidos por cursos das áreas de Engenharias e Biológicas (61,76\%) e versaram sobre diferentes temas, sendo que educação ambiental apresentou valores ínfimos $(2,32 \%)$. Em função da importância da área de ciências ambientais, pautada na perspectiva do desenvolvimento sustentável, sugere-se a promoção de ações que estimulem a execução de mais projetos nesta área.

Palavras-chave: Educação Ambiental; Ensino Superior; ODS; Pesquisa Científica.

${ }^{1}$ Centro Universitário de Maringá/ UNICESUMAR. E-mail: marcia.andreazzi@unicesumar.edu.br

2 Centro Universitário de Maringá/ UNICESUMAR. E-mail: ludhianamatos@gmail.com

${ }^{3}$ Centro Universitário de Maringá/ UNICESUMAR. E-mail: jose.santos@unicesumar.edu.br

${ }^{4}$ Centro Universitário de Maringá/ UNICESUMAR. E-mail: luiz.velho@unicesumar.edu.br

${ }^{5}$ Centro Universitário de Maringá/ UNICESUMAR. E-mail: isabele.picada@unicesumar.edu.br 


\section{Introdução}

O reconhecimento da importância da ciência e a necessidade de institucionalizar as ações de incentivo e fomento à pesquisa levaram o Brasil a criar, em 1951, o Conselho Nacional de Desenvolvimento Científico e Tecnológico - CNPq (MASSI; QUEIROZ, 2010) e, de acordo com o CNPq, existem vários programas de iniciação científica (IC) que servem como instrumento de apoio teórico e metodológico para a realização de projetos que contribuam para a formação profissional do aluno (BASTOS et al., 2010). Estes instrumentos de formação possibilitam engajar o estudante de graduação na pesquisa científica, com o recebimento de uma bolsa auxílio ou como voluntário, podendo ser voltada para os estudantes do ensino fundamental, médio e superior (CNPq, 2019).

Os programas do CNPq voltados para os estudantes do ensino superior incluem: o programa de bolsas de iniciação científica (PIBIC), primeiro programa de IC, criado em 1980 e o Programa Institucional de Bolsas de Iniciação em Desenvolvimento Tecnológico e Inovação Científica (PIBITI), criado em 2007, e dirigido somente às áreas tecnológicas e de inovação. Tanto o PIBIC quanto o PIBITI atendem instituições de ensino e/ou pesquisa públicas e/ou privadas oferecendo bolsas diretamente às instituições, que são responsáveis pela seleção e acompanhamento dos projetos. Já o Programa Institucional de Bolsas de Iniciação Científica nas Ações Afirmativas (PIBIC-Af), que é resultado de uma parceria entre CNPq e Secretaria Nacional de Políticas de Promoção da Igualdade Racial (SEPPIR), é dirigido somente às instituições públicas e aos estudantes que ingressaram no Ensino Superior por ação afirmativa, ou seja, possui o objetivo de corrigir desigualdades raciais presentes na sociedade (CNPq, 2019). Outra modalidade, uma parceria da Coordenação de Aperfeiçoamento de Pessoal de Nível Superior (CAPES) com o Instituto de Matemática Pura e Aplicada (IMPA), é o Programa de Iniciação Científica e Mestrado (PICME) que concede bolsas aos medalhistas da Olimpíada Brasileira de Matemática (OBM) que estejam cursando a graduação (CNPq, 2019).

Além destas categorias elencadas pelo CNPq, as Instituições de Ensino Superior (IES) podem oferecer outras modalidades com financiamento próprio. Por exemplo, o Centro de Ensino Superior de Maringá/ UNICESUMAR oferece bolsas de pesquisa pelo Programa de Bolsa de Iniciação Científica (PROBIC) e Programa de Iniciação Científica com Bolsa por Indução (PROIND) e, mesmo para os programas de pesquisa que, por natureza, não dispõe de bolsas para seus integrantes, como o Programa de Iniciação Científica (PIC), existe a modalidade Programa Prêmio de Iniciação Científica (PPIC), que confere aos melhores projetos um recurso financeiro como forma de incentivo à pesquisa (UNICESUMAR, 2019).

Independente da modalidade, destaca-se que todos os programas relacionados ao ensino superior buscam inserir e fixar o aluno no curso e na academia, desenvolver o pensamento científico, a iniciação à pesquisa e gerar conhecimento científico e, no caso do PIBIT, gerar produto ou processo de

revista brasileira educação ambiental 
produção, visando a inserção do aluno no setor empresarial (CNPq, 2019). Outras conquistas para um estudante que faz iniciação científica incluem uma melhor rotina de estudos, estrutura curricular diferenciada, leitura crítica, capacitação para a expressão oral e escrita e para habilidades manuais (FAVA DE MORAES; FAVA, 2000).

As pesquisas desenvolvidas pelas IC abordam temas amplos, variados e de diversas áreas e, a área de Ciências Ambientais (CA), pautada na temática sustentável vem ganhando espaço nas discussões, apesar de ainda ser um desafio no ensino superior (HUGÉ et al., 2016).

De fato, ressalta-se a expansão recente na demanda de conhecimentos e informações sobre questões ambientais e por isso, a área de CA tem se destacado. A CA surgiu pautada na perspectiva do desenvolvimento sustentável, com um conceito multidimensional e interdisciplinar que exige intercâmbio de conceitos, métodos e colaboração científica entre diversas áreas de conhecimento, como ecologia, mudança climática, sustentabilidade, química e educação ambiental que atuam, de forma isolada ou conjunta, para garantir o conhecimento essencial sobre o mundo em que vivemos e definir as ações de sustentabilidade ambiental (CAPES, 2016).

Desta forma, observa-se que as pesquisas na área de CA são essenciais para o desenvolvimento sustentável. Brundtland (1987) definiu desenvolvimento sustentável como as formas de progresso, baseado no crescimento econômico, proteção ao meio ambiente e igualdade social, que atendam às necessidades do presente sem comprometer a capacidade de as gerações futuras satisfazerem as suas necessidades.

Preocupados em garantir um desenvolvimento sustentável, em setembro de 2000, os líderes mundiais se reuniram na sede das Nações Unidas, para adotar a Declaração do Milênio da ONU, na qual, 191 nações se comprometeram, em uma parceria global, em reduzir a pobreza extrema, em uma série de oito objetivos, adotados até 2015, que ficaram conhecidos como os Objetivos de Desenvolvimento do Milênio (ODM). Ao final, os relatórios apontaram vários pontos positivos alcançados pelos ODM, contudo, evidenciaram fragilidades. Desta forma, foram definidos pelas Nações Unidas, os Objetivos do Desenvolvimento Sustentável (ODS), que compõem uma agenda global, adotada em setembro de 2015, totalizando 17 objetivos e 169 metas a serem atingidas até 2030 , que envolvem amplas e variadas ações que incluem acabar com a pobreza, promover a prosperidade e o bem-estar para todos, proteger 0 meio ambiente e enfrentar as mudanças climáticas (UNESCO, 2019).

Vários estudos têm analisado o perfil e a produção científica dos pesquisadores em diversos campos do conhecimento (BASTOS et al., 2010; MENDES et al., 2010; GONCALVES et al., 2014; ZAMPIERI et al., 2018), contudo, pesquisas que envolvam temas específicos, como é o caso da área de CA, e seus diferentes segmentos, são escassas na literatura. Portanto, pautados na importância, atualidade, complexidade e interdisciplinaridade das 
questões ambientais, o presente estudo teve como objetivo analisar a evolução dos projetos de iniciação científica relacionados à área de ciências ambientais, durante uma série histórica de 20 anos, em uma IES privada brasileira e a contribuição destes projetos para o desenvolvimento sustentável.

\section{Metodologia}

Foi realizado um estudo transversal quantitativo de caráter retrospectivo da evolução dos projetos de IC relacionados à área de CA utilizando uma série histórica de 20 anos, entre os anos de 1998 a 2018. Os dados foram disponibilizados pela Diretoria de Pesquisa de uma Instituição de Ensino Superior (IES) localizada na cidade de Maringá, região Noroeste do Paraná. Atualmente, a IES possui 11.000 alunos matriculados nos cursos presenciais, 190.000 alunos nos polos de educação à distância, 2.800 alunos em pós-graduação lato sensu e 250 alunos em pós-graduação stricto sensu.

A busca dos dados foi realizada em novembro de 2018 na base de dados da Diretoria de Pesquisa seguindo um protocolo de busca, análise e seleção nos títulos de 4.317 projetos de IC cadastrados.

A avaliação inicial verificou a aderência dos projetos as temáticas relacionadas às ciências ambientais, como meio ambiente, sustentabilidade, biodiversidade, bioeconomia, recuperação de áreas degradadas ou contaminadas, conservação do meio ambiente, desenvolvimento sustentável, produção sustentável, design verde de produtos, direito ambiental, manejo de resíduos, educação ambiental, dentre outros.

Do total de 4.317 projetos avaliados, somente 476 atenderam aos critérios de seleção e inclusão e, após, foram coletados os dados de: (a) ano de execução do projeto - para análise da evolução histórica; (b) categoria do programa de IC: com bolsa - PIBIC, PIBIT, PROBIC, PROIND e sem bolsa PPIC e PIC (Tabela 1); (c) agência de fomento: bolsa PIBIC concedida pela FUNADESP, CNPQ ou FA, bolsa PIBIT concedida pelo CNPq ou pelo ICETI, bolsa PROBIC concedida pelo ICETI ou prêmio PPIC concedido pelo ICETI (Tabela 1); (d) Grandes áreas do CNPq que o projeto pertence: agrárias, biológicas, engenharias, humanas, saúde e sociais aplicadas; (e) curso de graduação do projeto; (f) eixo temático (Figura 1).

Os dados foram tabulados, organizados em planilhas eletrônicas e avaliados por meio de estatística descritiva. 
Tabela 1: Categorias dos programas e Iniciação Científica (IC), agências de fomento e benefício financeiro concedido ao aluno.

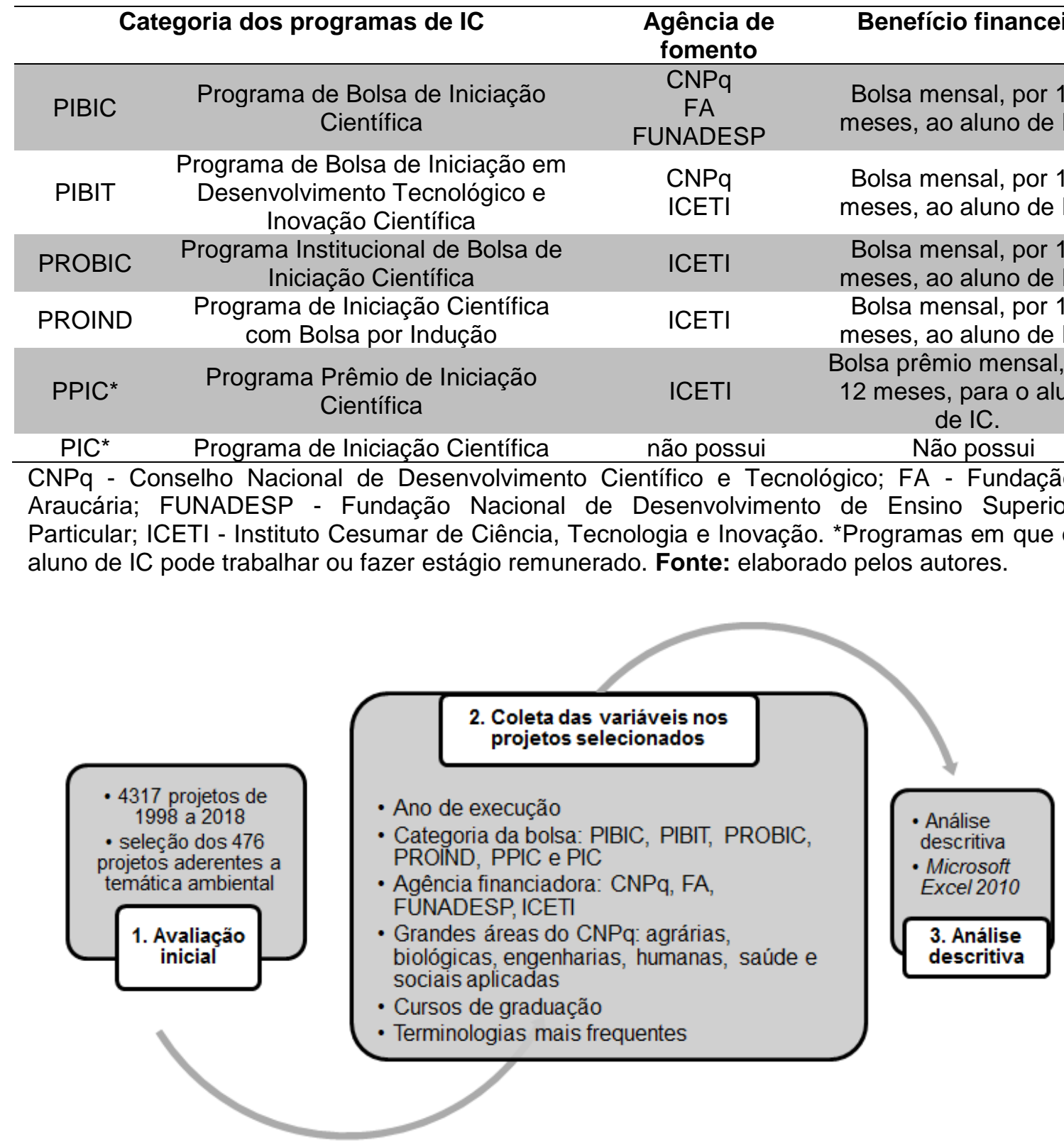

Figura 1: Delineamento experimental: etapas 1, 2 e 3 da pesquisa.

Fonte: elaborado pelos autores.

\section{Resultados e discussão}

Este estudo revelou uma diminuta quantidade de projetos desenvolvidos na IES, desde a implantação do Programa de Iniciação Científica em 1998, voltados à área de CA, somente 11\% (476/4.317). Essa reduzida quantidade de projetos é crítica, visto que, conforme definido CAPES (2016), os estudos na área de CA são multidisciplinares, complexos, abrangentes e, por isso, envolvem atividades sociais, econômicas e Revbea, São Paulo, V. 14, № 2: 152-164, 2019. 
tecnológicas e diferentes temas como água, energia, segurança alimentar, agricultura, dentre outros, além de buscar transpor os desafios teóricos e metodológicos da área. Em função da vasta abrangência da área, esperava-se um número maior de projetos.

Com relação à evolução histórica, o estudo permitiu identificar o número de projetos científicos de acordo com o triênio de execução, no período compreendido entre os anos de 1998 a 2018, evidenciando que o primeiro projeto relacionado à área de ciências ambientais foi desenvolvido em 2001 e, nos anos seguintes, o número de projetos apresentou um comportamento crescente, até meados de 2012, quando aumentou de forma expressiva (Figura 2 ), indicando que $71,64 \%$ (341/476) dos projetos foram desenvolvidos nos últimos 6 anos.

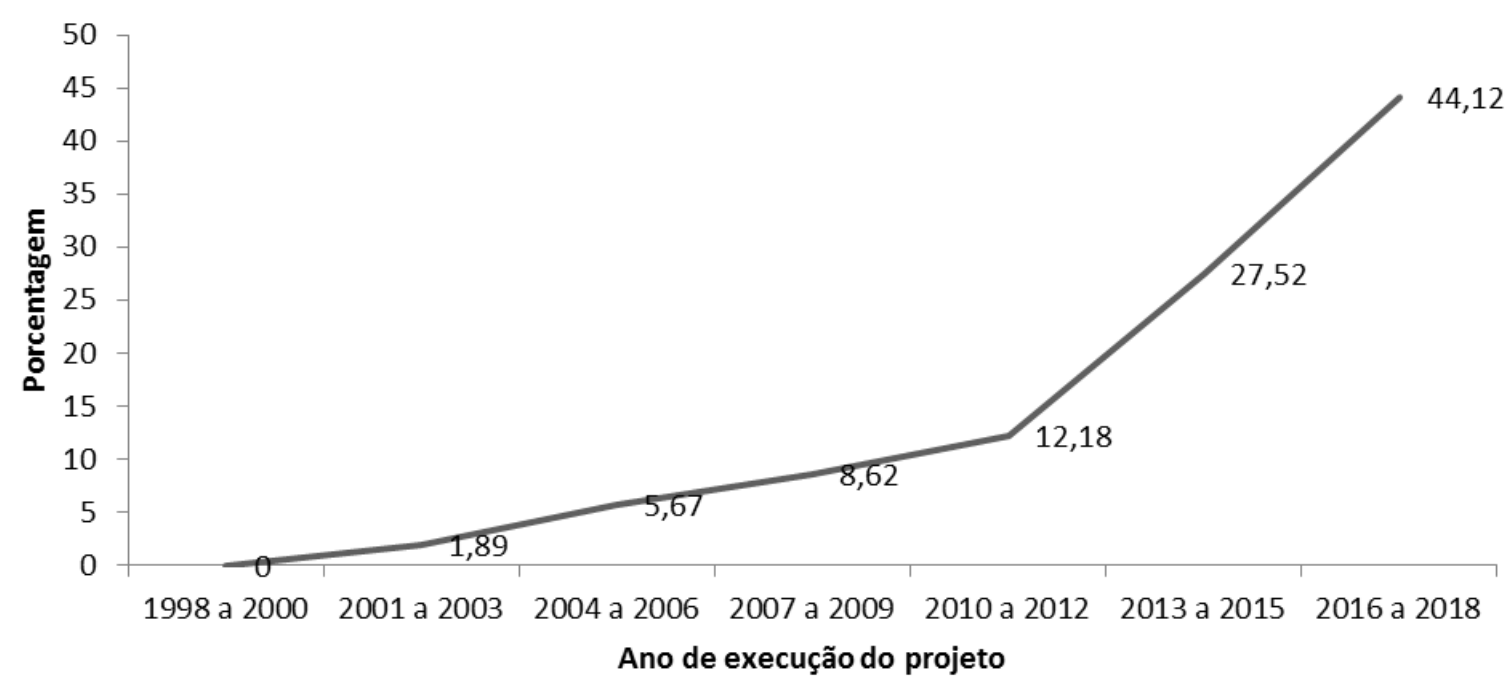

Figura 2: Porcentagem de projetos de iniciação científica, aderentes à área de ciências ambientais, executados em uma IES privada entre os anos de 1998 e 2018.

Fonte: elaborado pelos autores

Atribui-se o aumento na quantidade de projetos neste período a três fatores: primeiro, ao início das atividades dos cursos de graduação em Engenharia Civil (2008), Engenharia Ambiental e Sanitária (2010) e bacharelado em Ciências Biológicas (2011). Estes cursos apresentam notória correlação à área de CA, inclusive, como será discutido adiante, são os cursos que mais se destacaram quanto ao número de projetos desenvolvidos.

Segundo, credita-se parte deste aumento expressivo nos últimos anos, ao início das atividades do Programa de Pós-Graduação Stricto Sensu na área de Ciências Ambientais (2014) na IES. O referido curso de mestrado apresenta duas linhas de pesquisa, a "Ecoeficiência Urbana" e a "Agroindústria e Agropecuária Sustentável" que, com um caráter interdisciplinar, buscam entender a configuração e o desenho da interconectividade entre os sistemas sociais e ecológicos. Desta forma, vários docentes do mestrado, orientam, além dos projetos de mestrado, projetos de IC aderentes a estas linhas de pesquisa. 
O terceiro fator a ser considerado nesta evolução na quantidade de projetos de IC é o fato da IES ter se tornado signatária dos Objetivos de Desenvolvimento Sustentável (ODS), estimulando ações e projetos aderentes aos ODS. Os ODS foram elaborados de maneira a completar os Objetivos de Desenvolvimento do Milênio (ODM) e responder a novos desafios e visam orientar, nos anos de 2015 a 2030, as políticas nacionais e as atividades de cooperação internacional, por meio de 17 objetivos e 169 metas, integrados e indivisíveis, que mesclam, de forma equilibrada, as três dimensões do desenvolvimento sustentável, a econômica, a social e a ambiental (UNESCO, 2018).

Com relação às modalidades de programas de iniciação científica (Figura $3 \mathrm{~A}$ ), observou-se que a maioria (58\%) dos projetos desenvolvidos foi do tipo PIC, ou seja, sem auxílio financeiro, seguidos de projetos com auxílio institucional - PROBIC (22\%). Dos PIBIC's desenvolvidos com auxílio de agências de fomento (7\%), mais da metade dos recursos vieram do $\mathrm{CNPq}$ (Figura 3B) e, com relação ao PIBIT, os dados mostraram uma porcentagem ínfima de projetos $(2 \%)$, sendo a maior parte também financiada pelo $\mathrm{CNPq}$ (75\%) (Figura 3C).

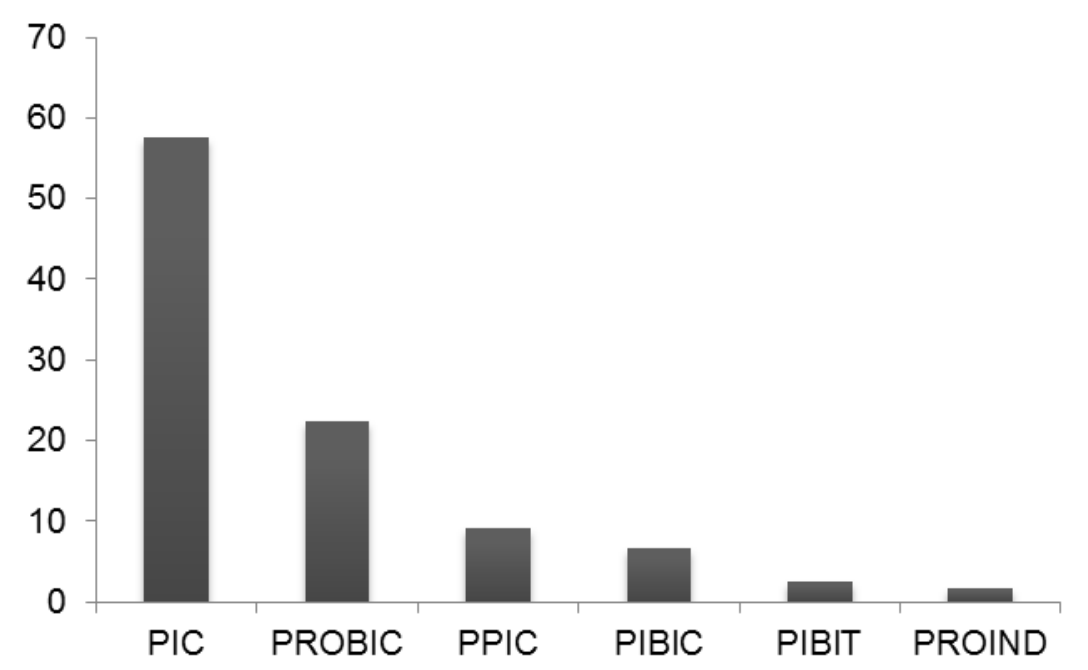

(A) Modalidades de programas de Iniciação Científica

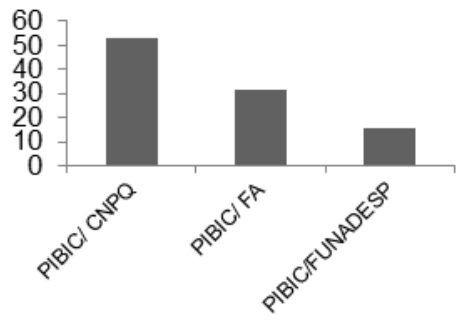

(B) Bolsas PIBIC

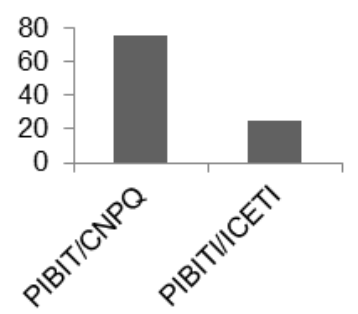

(C) Bolsas PIBIT

Figura 3: (A) Porcentagem de projetos de iniciação científica, aderentes à área de ciências ambientais, executados em uma IES privada entre os anos de 1998 e 2018, de acordo com a modalidade. (B) Porcentagem de projetos categoria PIBIC aderentes à área de ciências ambientais, executados em uma IES privada entre os anos de 1998 e 2018, de acordo com a agência de fomento. (C) Porcentagem de projetos categoria PIBIT aderentes à área de ciências ambientais, executados em uma IES privada entre os anos de 1998 e 2018, de acordo com a agência de fomento. Fonte: elaborado pelos autores. 
Os dados sobre a distribuição dos projetos de acordo com as grandes áreas do conhecimento, baseadas no CNPq, mostraram que mais da metade $(61,76 \%)$ foram desenvolvidos por alunos das áreas de Engenharias e Biológicas (Figura 4). A classificação das áreas do conhecimento tem o objetivo prático de proporcionar às instituições de ensino, pesquisa e inovação uma maneira ágil e funcional de sistematizar e prestar informações concernentes a projetos de pesquisa e recursos humanos aos órgãos gestores das áreas de ciência e tecnologia (CAPES, 2019). Hugé et al. (2016) relataram que discussões e projetos sobre sustentabilidade e meio ambiente vem se avolumando em todas as diferentes áreas e suas estratificações: agrárias, biológicas, engenharias, humanas, saúde e sociais aplicadas, contudo, contrariando os relatos do autor, esta pesquisa evidenciou somente duas áreas de destaque.

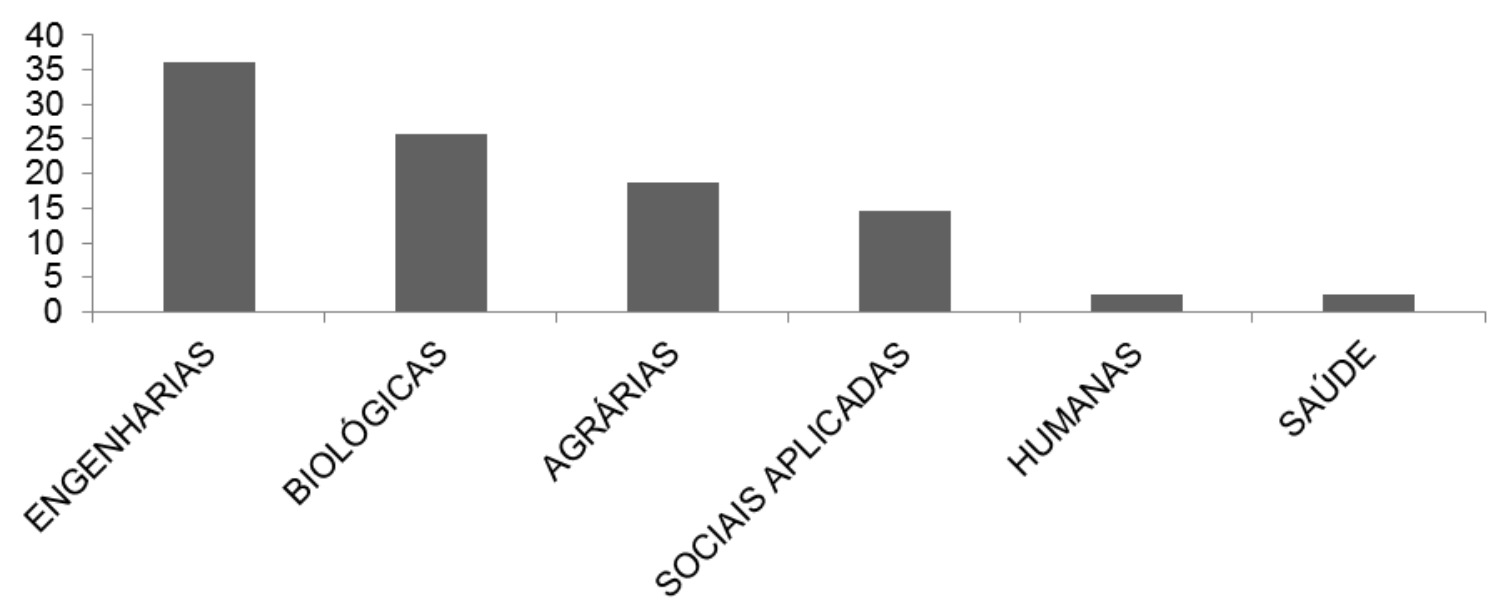

Figura 4: Porcentagem de projetos de iniciação científica, aderentes à área de ciências ambientais, executados em uma IES privada, entre os anos de 1998 e 2018, de acordo com as grandes áreas do CNPq. Fonte: elaborado pelos autores.

A fim de se obter informações mais objetivas, os dados foram investigados de acordo com os principais cursos de graduação envolvidos com o desenvolvimento dos projetos e, verificou-se que, os cursos de graduação em Ciências Biológicas, Engenharia Ambiental e Sanitária e Civil e Agronomia, pertencentes às grandes áreas de Engenharias e Biológicas, se destacaram com a maior parcela de projetos (65,76\%) (Figura 5).

Estes resultados reforçam as similaridades entre estes cursos de graduação no que tange às questões ambientais, pois, de modo geral, todos eles contemplam em seu projeto pedagógico tópicos como preservar os recursos naturais, proteger a saúde humana, reduzir os danos causados ao meio ambiente pelo homem e estimular a atuação crítica e criativa na identificação e resolução de problemas ambientais. 


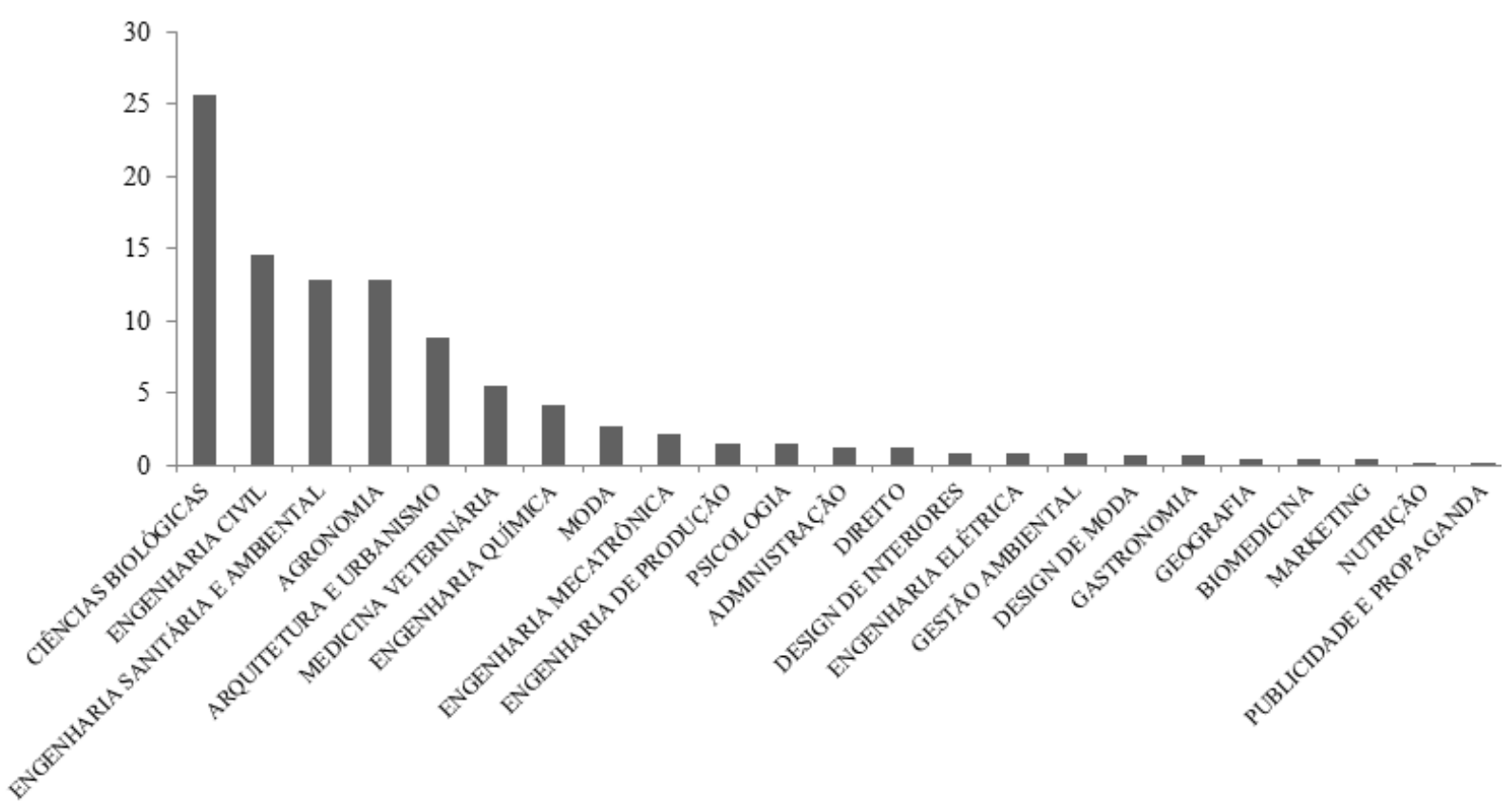

Figura 5: Porcentagem de projetos de iniciação científica, aderentes à área de ciências ambientais, executados em uma IES privada, entre os anos de 1998 e 2018, de acordo com os cursos de graduação. Fonte: elaborado pelos autores.

Com relação aos eixos temáticos (Figura 6), a pesquisa revelou uma grande variação, porém, estudos sobre resíduos $(14,3 \%)$, água $(12,6 \%)$, ambiente $(12,6 \%)$ e sustentabilidade $(7,77 \%)$ foram os que mais se destacaram, seguidos dos temas tratamentos de efluentes $(3,78 \%)$, concreto $(3,78 \%)$ e, em valores ínfimos, projetos sobre educação ambiental $(2,32 \%)$.

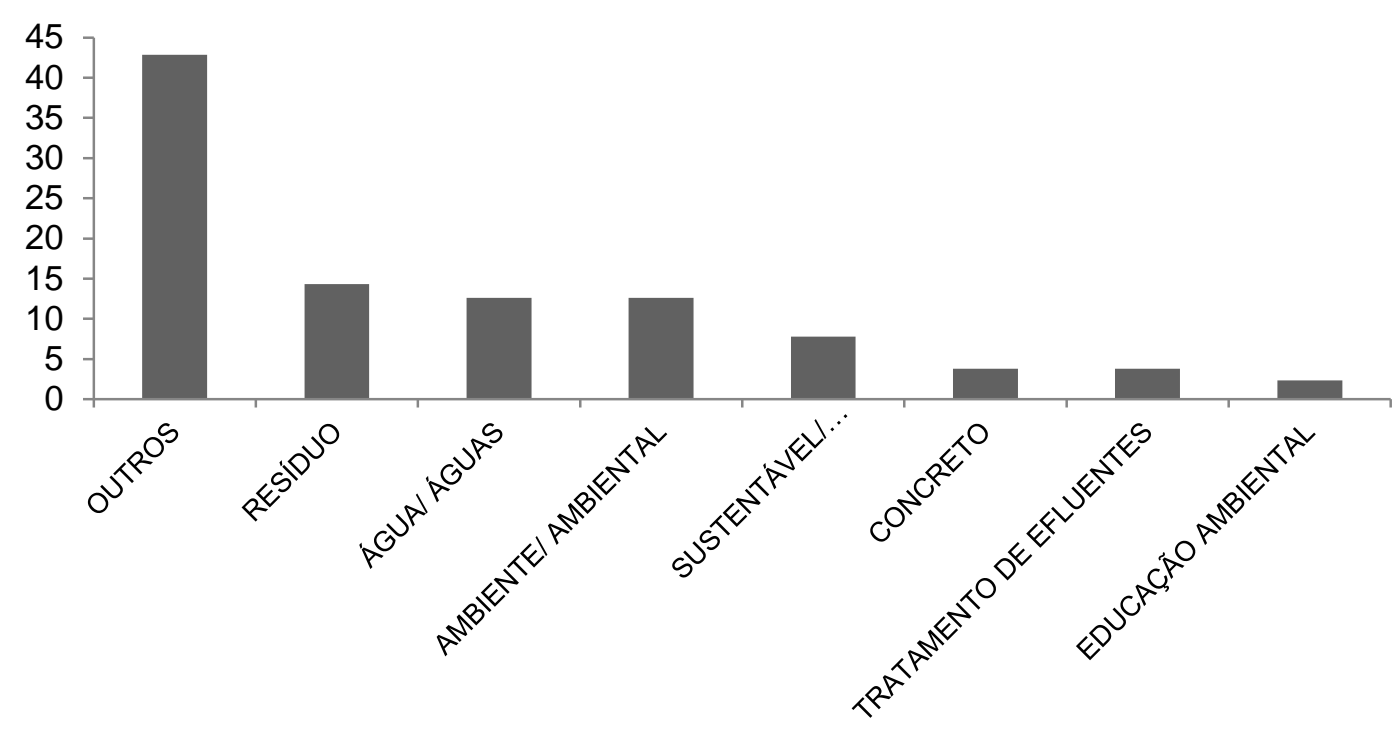

Figura 6: Porcentagem dos eixos temáticos mais ocorrentes nos projetos de iniciação científica executados em uma IES privada, entre os anos de 1998 e 2018.

Fonte: elaborado pelos autores.

Revbea, São Paulo, V. 14, № 2: 152-164, 2019. 
A análise histórica evidenciou o quanto estes assuntos são contemporâneos. No caso dos resíduos, uma lei brasileira atual, a Lei № 12.305, de 2 de agosto de 2010, instituiu a Política Nacional de Resíduos Sólidos, dispondo sobre seus princípios, objetivos e instrumentos, bem como sobre as diretrizes relativas à gestão integrada e ao gerenciamento de resíduos sólidos, às responsabilidades dos geradores e do poder público e os instrumentos econômicos aplicáveis (BRASIL, 2010). O decreto e sanção desta lei impulsionaram várias ações na sociedade e nas academias, refletindo nos projetos de iniciação científica.

Questões sobre água, ambiente e sustentabilidade seguem ao encontro da maioria dos ODS, que de modo geral, envolvem ações para acabar com a pobreza, promover a prosperidade e o bem-estar para todos, proteger o meio ambiente e enfrentar as mudanças climáticas (UNESCO, 2015). O ODS 6 versa exclusivamente sobre água e busca garantir a disponibilidade e manejo sustentável da água. Sendo assim, credita-se que este maior número de projetos tenha acontecido, motivados pelas atuais e crescentes discussões em torno dos ODS, além do caráter dos cursos já discutidos.

Os projetos na área de educação ambiental, apesar de terem sido elencados entre os sete temas mais abordados, apresentaram uma participação modesta nesta pesquisa. Este fato é lamentável, dada sua importância. A educação ambiental envolve valores, teorias e práticas que almejam a manutenção da vida e o enfrentamento da degradação socioambiental e, devido a relevância deste tema, foi criada a Lei № 9.795, em 27 de abril de 1999, que dispôs sobre a Educação Ambiental e instituiu a Política Nacional de Educação Ambiental (PNEA) (BRASIL, 1999). A Lei No 9.795 apontou que a educação ambiental é um processo no qual o indivíduo e a coletividade constroem valores sociais, conhecimentos, habilidades, atitudes e competências voltadas para a conservação do meio ambiente, essencial para uma vida saudável e sustentável, e deve estar presente, de forma articulada, em todos os níveis e modalidades do processo educativo (BRASIL, 1999), contudo, este fato não foi observado neste estudo, evidenciando uma fragilidade nos projetos de IC desenvolvidos pela IES que deve ser fortemente abordada.

Estudo recente que avaliou o PIBIC mostrou que estudantes que participam de programa de iniciação científica enquanto estão na graduação têm 2,2 vezes maior chance de completar o mestrado e 1,5 vezes maior de concluir o doutorado, quando comparados aos alunos que não participam do programa. A pesquisa também mostrou que estes alunos concluem a graduação mais jovem, apresentam uma remuneração $5 \%$ maior, além de outros benefícios, como por exemplo, $56 \%$ dos bolsistas declararam que, em função do PIBIC, tiveram contato com língua estrangeira e participaram de eventos para divulgar os resultados de suas pesquisas (CGEE, 2017). De fato, participar de projetos de IC, independente da modalidade, traz vários benefícios, como maior envolvimento do aluno no curso e na academia,

revista brasileira educação ambiental 
desenvolvimento do conhecimento e do pensamento científico (CNPq, 2019) além de proporcionar uma estrutura curricular diferenciada e melhor capacitação para a expressão oral e escrita, leitura e habilidades manuais (FAVA DE MORAES; FAVA, 2000). A experiência de IC contribui para o desenvolvimento de muitas competências e habilidades (MENEZES et al., 2013).

Contudo, para que o processo de IC tenha êxito em todas as suas dimensões, o ideal é que as pesquisas proporcionem além dos benefícios aos alunos envolvidos, o envolvimento de temáticas amplas e variadas, incluindo, por meio de pesquisas bibliográficas ou experimentais, diferentes estudos em diversas áreas, fato não observado neste estudo. Desta forma, a pesquisa permitiu observar várias lacunas neste processo no que tange a área de CA, sobretudo às questões sobre sustentabilidade, assunto tão atual e importante, pois além do reduzido número de projetos elencados no período avaliado, verificou-se que vários cursos e temas não foram revelados ou foram de forma limitada. Por exemplo, não foram detectados projetos relacionados aos cursos de graduação em Medicina e Farmácia, apesar de várias enfermidades estarem relacionadas às questões ambientais; o curso de Pedagogia também não desenvolveu nenhum projeto relacionado ao tema, mesmo reconhecendo a importância da Educação Ambiental na formação do pedagogo; o curso de Publicidade e Propaganda participou com somente $0,21 \%$ dos projetos e 0 curso de Direito, que conta em sua matriz curricular com a disciplina de Direito Ambiental, com somente $1,26 \%$ dos projetos.

De fato, Hugé et al. (2016) apontaram que a sustentabilidade no ensino superior é um campo crescente de reflexão e prática, mas sua integração com a pesquisa acadêmica ainda é considerada um desafio, fato que também foi observado neste estudo.

Para integrar e superar os desafios deve-se reconhecer que a CA é um campo interdisciplinar e, portanto, requer novas abordagens para educação e pesquisa em comparação com outras áreas. A abordagem interdisciplinar é intrínseca à área de $\mathrm{CA}$, o que significa um método de construção do conhecimento que se sustenta na compreensão da complexidade ambiental e na resolução de suas problemáticas que incorpora as demandas socioambientais na perspectiva do desenvolvimento sustentável (CAPES, 2016). Uma maneira viável de aumentar o papel da sustentabilidade no ensino superior é fomentar a pesquisa e o ensino interdisciplinar (AKTAS, 2015).

\section{Conclusões}

O estudo sobre a evolução histórica e a contribuição dos projetos de iniciação científica da IES avaliada demonstrou um número reduzido de projetos concernentes à área de Ciências Ambientais. Contudo, observou-se um aumento crescente no número de projetos a partir de 2015. Atribui-se parte deste progressivo aumento à preocupação institucional com o alcance dos ODS e a influência dos cursos de graduação em Ciências Biológicas, 
Engenharia Ambiental e Sanitária, Engenharia Civil e Agronomia, que atuam em parceria com o Mestrado na área de Ciências Ambientais da IES.

A maioria dos projetos desenvolvidos foi do tipo PIC e, apesar da grande variação nos eixos temáticos, a pesquisa demonstrou que projetos sobre resíduos, água, ambiente e sustentabilidade foram os que mais se destacaram, por outro lado, projetos sobre educação ambiental foram escassos.

Diante dos resultados encontrados, sugere-se a promoção de ações institucionais que estimulem a execução de mais projetos de IC integrados às diferentes temáticas da área de CA nos diferentes cursos, a fim de consolidar as atuações da IES enquanto signatária dos ODS e garantir aos alunos a formação científica, cidadã e interdisciplinar, pautada em pesquisas que colaborem com o desenvolvimento sustentável.

\section{Referências}

AKTAS C. B. Reflections on interdisciplinary sustainability research with undergraduate students. International journal of sustainability in higher education, v.16, p.354-366, 2015.

BASTOS, F.; MARTINS, F.; ALVES, M.; TERRA, M.; LEMOS, C.S. A importância da Iniciação Científica para os alunos de graduação em Biomedicina. Revista Eletrônica Novo Enfoque, v. 11, n.11, p.61-66, 2010.

BRASIL. Lei $\mathbf{N}^{\circ}$ 12.305, de 02 de agosto de 2010. Política Nacional de Resíduos Sólidos. Disponível em <www.planalto.gov.br/ccivil 03/ ato20072010/.../lei/l12305.htm>, acesso em: 20 mar. 2019.

BRASIL. Lei № 9.795, de 27 de abril de 1999. Política Nacional de Educação Ambiental. Disponível em <http://www.mma.gov.br/port/conama/legiabre. cfm?codlegi=321> acesso em: 11 mar. 2019.

BRUNDTLAND, G. H. Our common future: the world commission on environment and development. Oxford: Oxford University Press, 1987. 383p.

CENTRO DE GESTÃO E ESTUDOS ESTRATÉGICOS - CGEE. A Formação de novos quadros para CT\&I: avaliação do programa institucional de bolsas de iniciação. Brasília, DF. 2017. 175p. Disponível em $<$ https://www.cgee.org.br/documents/10195/734063/2373 PIBIC Relat\%C3\%B 3rio complcom.pdf> acesso em: 11 mar. 2019.

CENTRO DE ENSINO SUPERIOR DE MARINGÁ - UNICESUMAR. Diretoria de Pesquisa. Programas de Iniciação Científica. Disponível em $<$ https://www.unicesumar.edu.br/pesquisa/iniciacao-cientifica/> acesso em: 27 mar. 2019.

CONSELHO NACIONAL DE DESENVOLVIMENTO CIENTÍFICO E TECNOLÓGICO - CNPq. Disponível em <http://www.cnpq.br/web/guest/pibic/> acesso em: 11 mar. 2019.

revista brasileira educação ambiental 
COORDENAÇÃO DE APERFEIÇOAMENTO DE PESSOAL DE NÍVEL SUPERIOR - CAPES - disponível em <http://www.capes.gov.br/avaliacao/ instrumentos-de-apoio/tabela-de-areas-do-conhecimento-avaliacao > acesso em: 24 mar. 2019.

COORDENAÇÃO DE APERFEIÇOAMENTO DE PESSOAL DE NÍVEL SUPERIOR - CAPES. Diretoria de Avaliação. Documento de Área Ciências Ambientais. 43p. 2016. Disponível em <http://capes.gov.br/images/ documentos/Documentos de area 2017/49 CAMB docarea 2201 publ2.pdf> acesso em: 11 mar. 2019.

FAVA DE MORAES, F.; FAVA, M. A iniciação científica: algumas vantagens e alguns riscos. São Paulo em Perspectiva. v.14, n.1, p.73-77, 2000.

GONCALVES, E.; SANTOS, M. I. P.; MAIA, B. T.; BRANDÃO, R. C. S., OLIVEIRA, E. A.; MARTELLI JÚNIOR, H. Produção científica dos pesquisadores da área de pediatria no CNPq. Revista Brasileira de Educação Médica. v.38, n.3, p.349-355, 2014.

HUGÉ, J.; BLOCK, T.; WAAS, T.; WRIGHT, T.; DAHDOUH-GUEBAS, F.. How to walk the talk? Developing actions for sustainability in academic research. Journal of Cleaner Production. v..137, 2016, p.83-92, 2016.

MASSI L.; QUEIROZ, S.L. estudos sobre iniciação científica no Brasil: uma revisão, Cadernos de Pesquisa, v.40, n.139, p.173-197, 2010.

MENDES, P. H. C.; MARTELLI, D. R.B.; SOUZA, W. P.; QUIRINO FILHO, S.; MARTELLI JÚNIOR, H. Perfil dos pesquisadores bolsistas de produtividade científica em medicina no CNPq, Brasil. Revista Brasileira de Educação Médica. v. 34, n. 4, p.535-541. 2010.

MENEZES, J.R.; CARPES, P.B.M.; GONÇALVES, R.; VIEIRA, A.S.; BARROS, W.M.; VARGAS, L. A Importância da Iniciação Científica para o aluno de Graduação. Anais do Salão Internacional de Ensino, Pesquisa e Extensão. v.5, n.1, 2013.

ORGANIZAÇÃO DAS NAÇÕES UNIDAS PARA A EDUCAÇÃO A CIÊNCIA E A CULTURA - UNESCO - Agenda de Desenvolvimento Pós-2015 e os Objetivos de Desenvolvimento Sustentável. Disponível em $<$ http://www.unesco.org/new/pt/brasilia/post-2015-development-agenda/>, acesso em: 18 mar. 2019.

ZAMPIERI, V.H.; SANTIN, J.C.; SOUSA, K.M.C.; LOPES, H.S.S.; SANCHES, S.; SILVA, H.N.; ISHIKAWA, A.A.; ALMEIDA, A.P.F.; PONTES, F.M.; CAVALIN, R. Contribuições da iniciação científica no aprendizado e desenvolvimento dos estudantes no ensino superior. Revista de Ciências Sociais do Norte de Mato Grosso. v.7, v.1, 2018. 